\title{
Extraction of Arsenic(III) with Macroporous Resin Impregnated with Bis(2-ethylhexyl)ammonium Bis(2-ethylhexyl)- dithiocarbamate
}

\author{
Yoshito WAKuI*, Serigne A. NDIAYE**, Hideyuki MATSUnAGA*, Toshirou YokoYAma* \\ and Kenichi AKIBA**** \\ *Tohoku National Industrial Research Institute, Nigatake, Miyagino, Sendai 983-8551, Japan \\ **Faculty of Sciences and Techniques, Universite Cheikh Anta DIOP, Dakar, Senegal \\ ***Institute for Advanced Materials and Processing, Tohoku University, \\ Katahira, Aoba, Sendai 980-8577, Japan
}

\begin{abstract}
The extraction of arsenic(III) was investigated by using macroporous resin impregnated with a newly synthesized hydrophobic extractant: bis(2-ethylhexyl)ammonium bis(2-ethylhexyl)dithiocarbamate (BBDC). In a preliminary experiment on liquid-liquid extraction, arsenic(III) was favorably extracted with BBDC in heptane from acidic to neutral solutions; the distribution ratios with $0.01 \mathrm{~mol} \mathrm{dm}^{-3} \mathrm{BBDC}$ were larger than $10^{2.5}$ at $\mathrm{pH} 0-6$. The batchwise extraction of arsenic(III) with the impregnated resin was carried out. The distribution ratio was more than $10^{3}$ in an acidic region, and sharply decreased above $\mathrm{pH}$ 8. The collection of a trace amount of arsenic(III) was performed by using the column packed with the impregnated resin as a stationary phase. Then arsenic(III) retained on the column was quantitatively eluted out with an alkaline solution.
\end{abstract}

Keywords Solvent extraction, arsenic, dithiocarbamate, impregnated resin

Pollution by arsenic in natural and industrial waste water has been monitored and controlled to avoid its high toxicity to living things. In particular, advanced analytical methods have been required for the sensitive determination of the element, due to wide industrial use of arsenic, e.g., as GaAs semiconductors. Although the analytical instruments have been improved very much, selective separation of the element is usually required during the pretreatment of samples.

For the efficient preconcentration of metals, ion exchangeable resins having selective substituents have been receiving much attention. ${ }^{1,2}$ Macroporous resins impregnated with a selective reagent show similar advantages of solid-liquid and liquid-liquid extractions, that is, specific separation properties. ${ }^{3,4}$ Thus, the application of hydrophobic extractants to the impregnated resin is promising for designing an efficient separation process.

In a field of solvent extraction, dithiocarbamates have widely been employed in the preconcentration of arsenic, owing to their high extractability for arsenic(III). ${ }^{5-11}$ Among those compounds, diethyldithiocarbamate (DDTC) and piperidinedithiocarbamate (PDTC) have been frequently employed as an extractant. In spite of those favorable characteristics, such reagents still possess some disadvantages when they are applied to an impregnated resin; for example, they are almost insoluble in nonpolar solvents and readily released to an aqueous solution.

In this work, we have aimed to develop a novel col- umn separation system which can be utilized in the analysis of trace arsenic(III). We synthesized a new hydrophobic extractant, bis(2-ethylhexyl)ammonium bis(2-ethylhexyl)dithiocarbamate (BBDC), to be impregnated in a macroporous resin. The solvent extraction behavior of arsenic(III) was investigated using this reagent; moreover, the batchwise extraction to the resin on which the reagent was impregnated was carried out in order to examine the basic behavior of the reagent. Finally, chromatographic separation of arsenic(III) was performed through a column packed with the impregnated resin as a stationary phase.

\section{Experimental}

\section{Apparatus}

The concentration of metals was determined by a SEIKO ICP Atomic Emission Spectrophotometer (ICPAES), Model SPS-1200A. A shaking machine (Yamato shaker Model SA-31) and a centrifuge (Kubota KC-70) were used for the batchwise extraction. The $\mathrm{pH}$ was measured by a digital $\mathrm{pH}$ meter (TOA AUT-301).

\section{Reagents}

The extractant used here was synthesized along the following procedure. Bis(2-ethylhexyl)amine (Aldrich Company Inc., 99\%), $48.3 \mathrm{~g}(0.20 \mathrm{~mol})$ was placed in a round-bottomed flask with a thermometer. Carbon 
disulfide (Kanto Chemical Company Inc., >99\%) 7.61 $\mathrm{g}(0.10 \mathrm{~mol})$ was added dropwise with stirring at room temperature. When the temperature of the mixture exceeded $40^{\circ} \mathrm{C}$, the flask was cooled in a water bath to about $20^{\circ} \mathrm{C}$. The pale yellow mixture was stirred overnight. The viscous liquid which derived was analyzed with ${ }^{1} \mathrm{H}$ NMR and ${ }^{13} \mathrm{C}$ NMR. The yield was evaluated as $>90 \%$ by integrating the peaks. Little content of unreacted amine was suggested. The synthesized compound was used without further purification in subsequent experiments.

The stability of $10^{-4} \mathrm{M}$ BBDC in heptane solution was checked by measuring UV absorbance at $286 \mathrm{~nm}$ at $25^{\circ} \mathrm{C}$. The absorbance decreased to $84 \%$ after $2 \mathrm{~d}$, $79 \%$ after $7 \mathrm{~d}$ and $71 \%$ after $19 \mathrm{~d}$. The extractant and its solutions were stored in a refrigerator and used within a week after preparation.

A stock solution of arsenic was prepared by dissolving arsenic(III) oxide $\left(\mathrm{As}_{2} \mathrm{O}_{3}\right.$, Kojundo Chemical Laboratory Co. Ltd., 99.999\%). The oxide $(0.5 \mathrm{~g})$ was mixed with $2 \mathrm{~cm}^{3}$ of $1 \mathrm{M}\left(\mathrm{M}=\mathrm{mol} \mathrm{dm} \mathrm{dm}^{-3}\right)$ sodium hydroxide and stirred overnight at room temperature. It was acidified with hydrochloric acid and then diluted to $250 \mathrm{~cm}^{3}$.

The arsenic(III) solution free from $\operatorname{arsenic}(\mathrm{V})$ was prepared by the following procedure: $10 \mathrm{~cm}^{3}$ of the stock solution was diluted to $100 \mathrm{~cm}^{3}$ with concentrated hydrochloric acid and was shaken with an equal volume of benzene to extract arsenic(III); ${ }^{11,12}$ then arsenic(III) was stripped with an aqueous solution containing $0.01 \mathrm{M}$ hydrochloric acid and $0.01 \mathrm{M}$ ascorbic acid. The concentration of arsenic in the solution was determined by ICP-AES.

The arsenic $(\mathrm{V})$ solution was prepared by oxidizing the arsenic(III) by the addition of an excess amount of hydrogen peroxide. ${ }^{11}$

The $\mathrm{pH}$ values were controlled by partially neutralizing such buffers as 2-morpholinoethanesulfonic acid (MES, $\mathrm{p} K_{\mathrm{a}}=6.15$ ), 3-morpholinopropanesulfonic acid (MOPS, $\mathrm{p} K_{\mathrm{a}}=7.20$ ), $N$-tris(hydroxymethyl)methyl-3aminopropanesulfonic acid (TAPS, $\mathrm{p} K_{\mathrm{a}}=8.4$ ), $N$-cyclohexyl-2-aminoethanesulfonic acid (CHES, $\mathrm{p} K_{\mathrm{a}}=9.5$ ) and $N$-cyclohexyl-3-aminopropanesulfonic acid (CAPS, $\left.\mathrm{p} K_{\mathrm{a}}=10.40\right)$ (DOJINDO Laboratories)..$^{13,14}$ Inorganic acids and heptane were of analytical grade, and the other chemicals were of guaranteed grade.

\section{Resin beads}

Amberlite XAD-7 (polyacrylate, Rohm and Haas Company) of $20-60$ mesh having a surface area of 450 $\mathrm{m}^{2} / \mathrm{g}$ and a mean pore diameter of $90 \AA$ was used as a polymer support. Resin beads ( $200 \mathrm{~g})$ were immersed in $500 \mathrm{~cm}^{3}$ of acetone, left overnight, filtrated, rinsed with acetone, and dried with a rotary evaporator. They were successively washed with $0.1 \mathrm{M}$ nitric acid and acetone in a similar manner, then dried in vacuo.

Eight grams of BBDC were dissolved in $50 \mathrm{~cm}^{3}$ of acetone and placed in contact with $20 \mathrm{~g}$ of washed XAD-7. After the mixture was stirred under reduced pressure for $1 \mathrm{~h}$, acetone was evaporated off and the resin was dried under vacuum.

\section{Solvent extraction}

An aqueous solution containing $1 \times 10^{-4} \mathrm{M}$ arsenic(III) adjusted to the desired $\mathrm{pH}$ value and a heptane solution containing BBDC were shaken in a room thermostated at $25^{\circ} \mathrm{C}$. After centrifuging, an aliquot of aqueous phase was taken out for the ICP measurement. Ionic concentration was usually adjusted to $0.1 \mathrm{M}$ with sodium chloride. In the measurements of the distribution ratio at low and high $\mathrm{pH}$ area, the organic phase was preliminarily shaken with the aqueous solution containing no arsenic to maintain the $\mathrm{pH}$ value. The distribution ratio $(D)$ was obtained as the ratio of the concentration of arsenic in the organic phase to that in the aqueous phase.

\section{Batchwise extraction on impregnated resin}

The extraction of arsenic(III) on the resin was examined by placing a resin $(0.1 \mathrm{~g})$ impregnating BBDC in contact with an aqueous phase $\left(5\right.$ or $\left.10 \mathrm{~cm}^{3}\right)$ containing $1 \times 10^{-4} \mathrm{M}$ of arsenic(III) in a thermostated room at $25^{\circ} \mathrm{C}$. After filtration, the concentration of the elements remaining in the aqueous phase was determined by ICP-AES, and the distribution ratio $\left(D_{\mathrm{r}}\right)$ was obtained as the ratio of the content in the resin $(\mathrm{mmol} / \mathrm{g})$ and the concentration in aqueous solution (M).

\section{Column separation}

The impregnated resin was immersed in an aqueous solution free from metal ions for $3 \mathrm{~h}$. Then it was packed into a glass column $(\phi 1.5 \mathrm{~cm}$ i.d. $)$, and plastic tubes were connected to the inlet and outlet of the column. A sample solution containing arsenic(III) was continuously fed into the column at a flow rate of 24 $\mathrm{cm}^{3} / \mathrm{h}$ by a peristaltic pump. The effluent was fractionated into portions of $7-8 \mathrm{~cm}^{3}$ and the arsenic concentration in each fraction was determined by ICP-AES.

\section{Results and Discussion}

\section{Solvent extraction}

Distribution behavior of arsenic(III) was investigated to check the basic characteristics of BBDC in an extraction system. Distribution coefficient of BBDC between 0.01 M BBDC heptane solution and an aqueous solution at $\mathrm{pH} 6.1$ was found to be over $10^{4}$ by spectrophotometric data, implying that the reagent is only slightly soluble in water.

No extraction of arsenic(III) with $1 \times 10^{-2} \mathrm{M}$ bis(2-ethylhexyl)amine, which was a possible impurity in the reagent, was observed, thus, amine impurity would give no effect on the $D$ values.

Dependence of the $\log D$ values of arsenic(III) on the extraction time was examined at $\mathrm{pH}$ 6.4. The $\log D$ value of arsenic(III) increased along with shaking time; 1.7 at $30 \mathrm{~min}, 2.2$ at $1 \mathrm{~h}$ and 2.3 at $4 \mathrm{~h}$, and then became 
almost constant. A similar result was obtained at $\mathrm{pH}$ 5.8. Then the shaking time for the solvent extraction was fixed at $6 \mathrm{~h}$.

The relationship between $\log D$ and $\mathrm{pH} 0-11$ is shown in Fig. 1. Arsenic(III) was quantitatively extracted from the acidic aqueous phase to the organic phase, yielding $\log D$ values of around 3 in a $\mathrm{pH}$ region of $0-2$. This is an attractive feature not only for analytical separation but also for the industrial processes. The distribution ratio of arsenic(III) gradually decreased along with the change of $\mathrm{pH}$ from acidic to alkaline area, and no $D$ value could be obtained above pH 11 because of emulsification.

Figure 2 shows plots of $\log D$ values against $\log [\mathrm{BBDC}]_{\mathrm{o}}$ in heptane. At the higher BBDC concentration above $2 \times 10^{-3} \mathrm{M}, \log D$ values were almost constant. On the other hand, $D$ values decreased in the

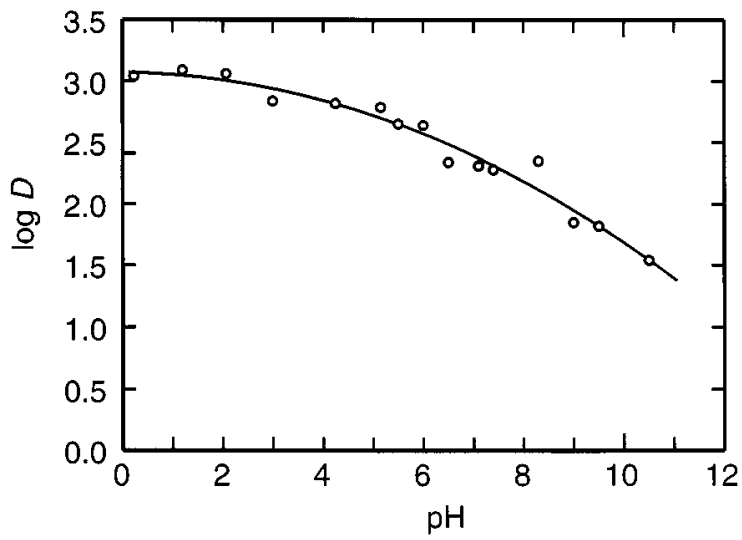

Fig. 1 Distribution ratio of arsenic(III) between heptane containing 0.01 $\mathrm{M} \mathrm{BBDC}$ and the aqueous solution as a function of $\mathrm{pH} . \quad I=0.1 \mathrm{M}(\mathrm{HCl}-\mathrm{NaCl})$ when $[\mathrm{HCl}]<0.1 \mathrm{M}$. $[\mathrm{As}]_{\mathrm{i}}=1 \times 10^{-4} \mathrm{M}$. [Buffer $]=1 \times 10^{-3} \mathrm{M}$ when $\mathrm{pH}>4 . V_{\mathrm{a}}=10 \mathrm{~cm}^{3}$. $V_{\mathrm{o}}=3 \mathrm{~cm}^{3}$. Shaking for $6 \mathrm{~h}$ at $25^{\circ} \mathrm{C}$.

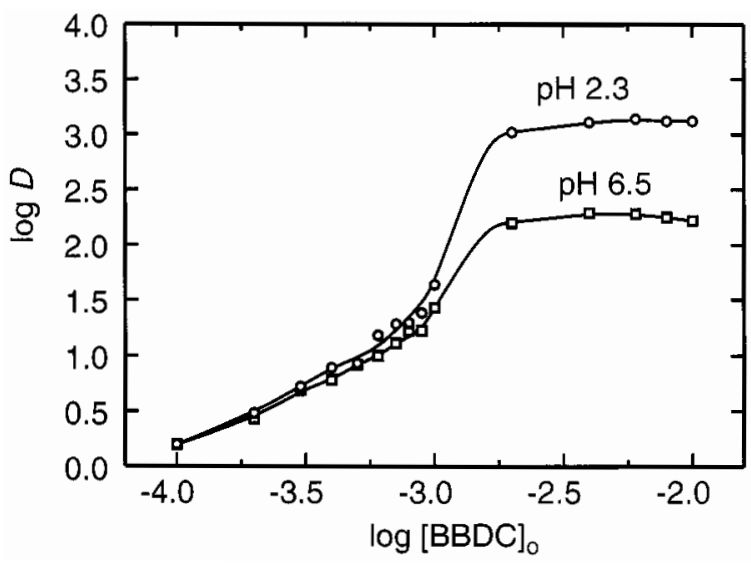

Fig. 2 Distribution ratio of arsenic(III) between heptane containing BBDC and the aqueous solution as a function of the concentration of BBDC. $[\mathrm{As}]_{\mathrm{i}}=1 \times 10^{-4} \mathrm{M}$. $[\mathrm{NaCl}]=0.1 \mathrm{M}$ at $\mathrm{pH}=6.5$. $[\mathrm{MES}]=1 \times 10^{-3} \mathrm{M}$ at $\mathrm{pH}=6.5 . V_{\mathrm{a}}=10 \mathrm{~cm}^{3} . V_{\mathrm{o}}=3$ $\mathrm{cm}^{3}$. Shaking for $6 \mathrm{~h}$ at $25^{\circ} \mathrm{C}$. lower BBDC concentration below $1 \times 10^{-3} \mathrm{M}$, due to a shortage of amount of reagent compared to that of arsenic(III). At the point at $[\mathrm{BBDC}]_{0}=1 \times 10^{-3} \mathrm{M}$, the molar ratio of total arsenic(III) against BBDC was $1: 3$ under the extracting conditions. This ratio corresponds to the composition of the extracted species. This finding is analogous to those reported for other dithiocarbamate extractants. ${ }^{15,16}$

The influences of metal ions on the extraction of arsenic(III) were examined in the presence of $1 \times 10^{-4} \mathrm{M}$ of each ion. The $\log D$ values of arsenic(III) were 1.8 with manganese(II), 1.2 with iron(III), 1.4 with nickel(II), 1.1 with copper(II), 1.9 with zinc(II), 2.1 with cadmium(II) and 2.2 with lead(II), respectively. Compared with the case $(\log D=3.1)$ without diverse ions, the distribution was suppressed in the presence of these ions; this was especially significant for iron(III) and copper(II). Such interferences would be caused by the association of arsenite ion with the coexisting metal cations. ${ }^{17,18}$ These interferences would be eliminated in the presence of appropriate masking agents which react with metal cations but not with arsenic(III), e.g., EDTA and tartrate..$^{5}$

Extraction of the coexisting metals was examined under the same conditions. Copper(II) and cadmium(II) were completely extracted. The $\log D$ values of iron(III), zinc(II) and lead(II) were found to be 2.0, 2.6 and 2.4 respectively, while no extraction was observed for manganese(II) and nickel(II).

Figure 3 shows the effect of the concentration of coexisting metal ions. The $\log D$ value of arsenic(III) remained nearly constant independent of zinc(II) concentration, whereas it decreased along with increasing concentrations of copper(II) and iron(III). Reproducibility was found to be lower in the presence of copper(II) and iron(III); about \pm 0.3 in $\log D$. The extraction of arsenic(V) with $0.01 \mathrm{M} \mathrm{BBDC}$ was also examined in the range of $\mathrm{pH} 0-8$, but $\operatorname{arsenic}(\mathrm{V})$ was not extracted at all.

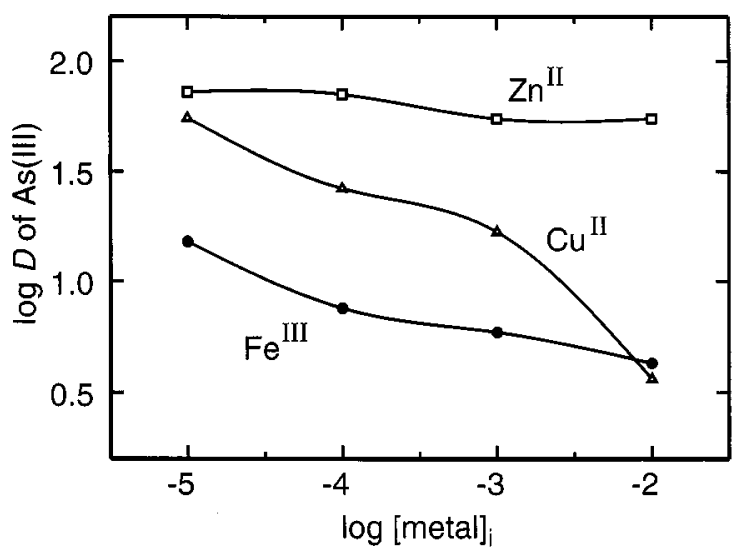

Fig. 3 Distribution ratio of arsenic(III) in the presence of other metal ions. $[\mathrm{BBDC}]_{0}=0.01 \mathrm{M}$ in heptane. $[\mathrm{As}]_{\mathrm{i}}=1 \times 10^{-4}$ M. $\mathrm{pH}=2.0 . I=0.1 \mathrm{M}(\mathrm{HCl}-\mathrm{NaCl}) .[\mathrm{HCl}]=0.01 \mathrm{M} . V_{\mathrm{a}}=10 \mathrm{~cm}^{3}$. $V_{\mathrm{o}}=3 \mathrm{~cm}^{3}$. Shaking for $6 \mathrm{~h}$ at $25^{\circ} \mathrm{C}$. 
The newly synthesized extractant is thus available for the extraction of arsenic(III) with a high distribution ratio. This may provide an impregnated resin having high affinity to arsenic(III).

\section{Batchwise extraction in resin system}

The distribution equilibrium of arsenic(III) with BBDC impregnated resin was checked by varying the shaking time. The BBDC impregnated resin $(0.1 \mathrm{~g})$ was shaken with the aqueous phase $\left(5 \mathrm{~cm}^{3}\right)$ containing $1 \times 10^{-4} \mathrm{M}$ of arsenic(III) and $0.01 \mathrm{M}$ of hydrochloric acid. The $\log D_{\mathrm{r}}$ value increased with shaking time: 3.6 at $15 \mathrm{~min}, 3.6$ at $30 \mathrm{~min}$, and 3.7 at $1 \mathrm{~h}$, and after that remained unaltered for $19 \mathrm{~h}$. Then the shaking time was fixed to $3 \mathrm{~h}$ in subsequent experiments.

The dependence of the distribution ratio of arsenic(III) on $\mathrm{pH}$ was examined in the impregnated resin system. As shown in Fig. 4, the $\log D_{\mathrm{r}}$ value gradually decreased along with an increase in $\mathrm{pH}$ and sharply dropped at $\mathrm{pH}=8-9$, over which little arsenic was extracted into the resin. Emulsification was not observed in the alkaline region. These trends probably correspond to the fact that a neutral species of arsenic(III), $\mathrm{H}_{3} \mathrm{AsO}_{3}$, is predominant in acidic and neutral region and it dissociates to an anion at the higher $\mathrm{pH}$, i.e., $\mathrm{p} K_{\mathrm{a} 1}=9.1\left(25^{\circ} \mathrm{C}, I=0.1 \mathrm{M}\right) .^{19}$ These findings imply that the extraction of arsenic(III) into the resin impregnated with BBDC would be effectively accomplished in the acidic region, yielding $\log D_{\mathrm{r}}$ values above 3.5 at the maximum, and then the arsenic extracted on the resin could be recovered by coming in contact with an alkaline solution.

The influence of diverse metal ions was examined under the following conditions; $V_{\mathrm{a}}=5 \mathrm{~cm}^{3}$, weight of resin $W_{\mathrm{r}}=0.1 \mathrm{~g}, \mathrm{pH}=2.0$, initial concentration of arsenic(III) and coexisting metal ion $=1 \times 10^{-4} \mathrm{M}$. The $\log D_{\mathrm{r}}$ values of arsenic(III) were 2.6 with manganese (II), 2.2 with iron(III), 2.5 with nickel(II), 1.9 with copper(II), 2.5 with zinc(II), 2.5 with cadmium(II) and 2.5 with lead(II). Interference effects of these metal ions were similar to those in the solvent extraction system.

The distribution ratios of coexisting metals were also obtained: $\log D_{\mathrm{r}}=2.2$ for manganese(II), 3.2 for iron(III) and $\log D_{\mathrm{r}}>3.5$ for the others. Thus this resin is effective for the simultaneous uptake of many heavy metals, but rather unsuitable for the specific separation of arsenic.

\section{Column procedure}

Collection of a trace amount of arsenic(III) was attempted by using a column packed with BBDC impregnated resin $(9 \mathrm{~g}, \phi 1.5 \times 27 \mathrm{~cm})$. A solution containing $1.0 \times 10^{-5} \mathrm{M}$ of arsenic(III) was continuously passed through the column and the arsenic concentration in the effluent was determined. Figure 5 shows the breakthrough curve of arsenic(III). During the almost 50 -fold of the column volume, the arsenic concentration was kept under $3 \times 10^{-7} \mathrm{M}$.
The elution of arsenic(III) was performed with a 0.1 $M$ sodium hydroxide solution after the retention of a known amount of arsenic(III) in the column. As Fig. 6 shows, the arsenic(III) retained was readily eluted out with the eluant of about 2-fold of the column volume, yielding the quantitative recovery $(99.6 \%)$.

The BBDC impregnated resin was readily prepared; it was proved to have some potentials for preconcentration of arsenic(III) from diluted solutions. The high $D$ value in an acidic region enables the quantitative capture with the high concentration factor of arsenic(III): for example, extracting arsenic(III) on the resin from the $2 \mathrm{dm}^{3}$ solution and releasing it with $100 \mathrm{~cm}^{3}$ alkaline solution can realize 20-fold concentration. These features can also be obtained in a column process, where the retention and the elution are performed by a flow system. This resin in conjunction with instrumen-

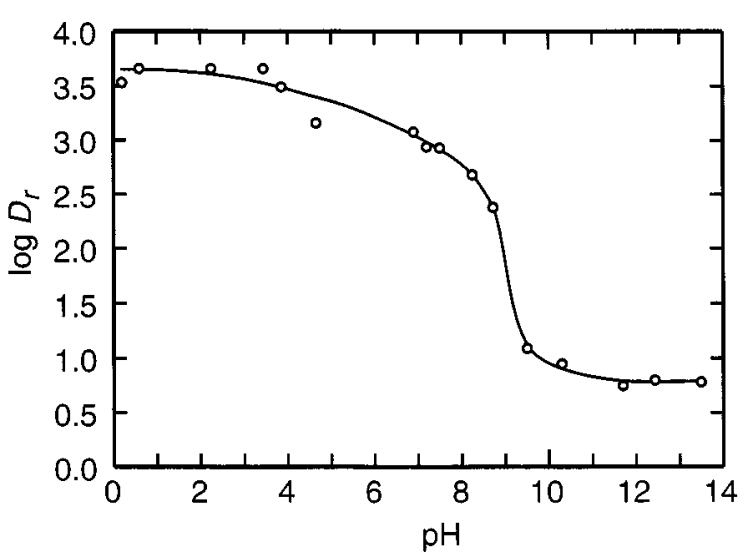

Fig. 4 Distribution ratio of arsenic(III) between the BBDC impregnated resin and the aqueous solution as a function of pH. Resin: Amberlite XAD-7 impregnated with BBDC (29 wt $\%)$. $[\mathrm{As}]_{\mathrm{i}}=1 \times 10^{-4}$ M. $I=0.1 \mathrm{M}$ when $[\mathrm{HCl}]<0.1 \mathrm{M}$. [Buffer $]$ $=1 \times 10^{-3} \mathrm{M}$ when $\mathrm{pH}>4 . V_{\mathrm{a}}=5 \mathrm{~cm}^{3} . W_{\mathrm{r}}=0.10 \mathrm{~g}$. Shaking for 3 h at $25^{\circ} \mathrm{C}$.

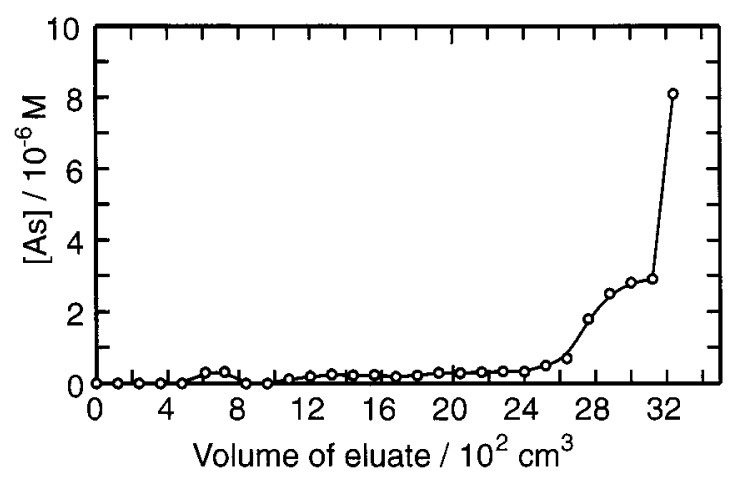

Fig. 5 Breakthrough curve of arsenic(III) through the column packed with BBDC impregnated resin. Resin: Amberlite XAD-7 impregnated with BBDC (29 wt \%). Column: $1.5 \mathrm{~cm}$ (i.d.) $\times 27 \mathrm{~cm}$. $[\mathrm{As}]_{\mathrm{i}}=1 \times 10^{-5} \mathrm{M} . I=0.1 \mathrm{M}(\mathrm{NaCl}-\mathrm{HCl})$. $[\mathrm{HCl}]=$ $0.01 \mathrm{M}$. Flow rate $=24 \mathrm{~cm}^{3} / \mathrm{h}$. 


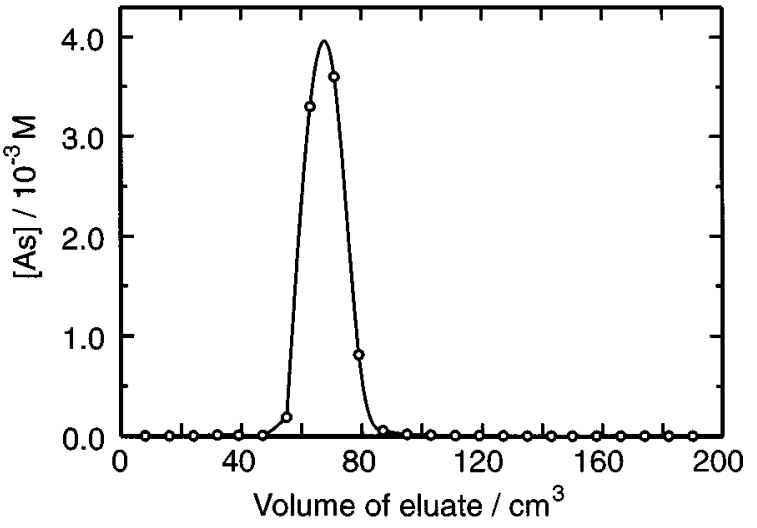

Fig. 6 Recovery of arsenic(III) retained on the BBDC impregnated resin column. Resin: Amberlite XAD-7 impregnated with BBDC (29 wt \%). Column: $1.5 \mathrm{~cm}$ (i.d.) $\times 27 \mathrm{~cm}$. $[\mathrm{NaOH}]=0.1 \mathrm{M}$. Retained amount of $\operatorname{arsenic}(\mathrm{III})=6.5 \times 10^{-5}$ mol. Flow rate $=24 \mathrm{~cm}^{3} / \mathrm{h}$.

tal techniques will contribute to lower the detection limit.

\section{References}

1. J. Minczewski, J. Chwastowska and R. Dybczyñski, "Separation and Preconcentration Methods in Inorganic Trace Analysis", Ellis Horwood, Chichester, 1982.

2. M. Marhol, "Ion Exchangers in Analytical Chemistry. Their Properties and Use in Inorganic Chemistry", ed. G. Svehla, Elsevier, Amsterdam, 1982.
3. A. Warshawsky, in "Ion Exchange and Solvent Extraction", ed. J. A. Marinsky and Y. Marcus, Vol. 8, Chap. 3, Marcel Dekker, New York, Basel, 1981.

4. J. R. Parrish, Anal. Chem., 49, 1189 (1977).

5. A. Hulanicki, Talanta, 14, 1371 (1967).

6. A. G. Howard and M. H. Arbab-Zavar, Analyst [London], 105, 338 (1980).

7. W. M. Mok, N. K. Shah and C. M. Wai, Anal. Chem., 58, 110 (1986).

8. W. M. Mok and C. M. Wai, Anal. Chem., 59, 233 (1987).

9. G. R. Bradford and D. Bakhtar, Environ. Sci. Technol., 25, 1704 (1991).

10. H. Hasegawa, Y. Sohrin, M. Matsui, M. Hojo and M. Kawashima, Anal. Chem., 66, 3247 (1994).

11. N. Suzuki, K. Satoh, H. Shoji and H. Imura, Anal. Chim. Acta, 185, 239 (1986)

12. C. Sella, R. N. Mendoza and D. Bauer, Hydrometallurgy, 27, 179 (1991).

13. T. Imamura and M. Saito, Kagaku no Ryoiki (Journal of Japanese Chemistry), 30, 167 (1976).

14. S. Funahashi and S. Yamada, Bunseki, 1983, 388 (1983).

15. J. Starý and J. Prášilová, Radiochem. Radioanal. Lett., 18, 99 (1974).

16. H. Förster, J. Radioanal. Chem., 4, 1 (1970).

17. T. Nishimura, C. T. Itoh and K. Tozawa, Tohoku Daigaku Sozai Kogaku Kenkyusho Iho, 48, 97 (1992).

18. T. Golgotiu, I. Rosca, V. Rotaru, M. Apostolescu and E. Stefancu, Rev. Chim., 26, 733 (1975); [Chem. Abstr., 84, 50530 (1976)].

19. R. M. Smith and A. E. Martell, "Critical Stability Constants”, Vol. 4, p. 132, Plenum, New York, 1976.

(Received June 30, 1997)

(Accepted November 6, 1997) 